\title{
El relato autobiográfico, entre ficción y testimonio
}

\author{
Carlos Mario Fisgativa (UNIQUINDÍO - UBA)* \\ https://orcid.org/0000-0001-5213-8675
}

\section{Resumen:}

Proponemos explorar el nexo entre testimonio, autobiografía y literatura así como la indistinción que se da entre el relato testimonial o la ficción poética. En esta línea de indagación nos resulta útil remitir a Demeure, Maurice Blanchot, escrito en el que Jacques Derrida comenta el texto El instante de mi muerte, para mostrar que no es posible la distinción completa entre el registro del relato, el de la autobiografía y el del testimonio. Puesto que el escrito de Blanchot hace ver que la atestación tiene una relación complicada con la ficción, ya que sus límites se contaminan y que se da la indecidibilidad entre lo autobiográfico y lo heterotanatográfico, entre el lenguaje performativo y el constatativo, ya que recurren a procedimientos comunes como son la narración, la promesa de ser verosímiles, de poder repetirse; a su vez, son discursos en "primera persona" que hablan de una experiencia o de sí mismos. En consecuencia, el sujeto que se narra, la voz que enuncia es un efecto que se produce por la narración o atestación misma.

Palabras clave: Relato, Testimonio, Ficción, Autobiografía.

\section{Abstract:}

\section{Autobiographic Tale: between fiction and testimony}

We will explore the link between testimony, autobiography and literature, as well as the indistinction between testimonial relate and poetical fiction. In this line of inquiry, it is useful to do reference to Demeure, Maurice Blanchot, writing in which Jacques Derrida comments the book The instant of my death, to show the impossibility of a fully distinction of the relate register from autobiography and testimony. Given that the Blanchot's text let us see that testifying holds a difficult relationship to fiction, because their limits contaminate each other, implying the undecidability of autobiography and heterotanatography, of performative and constitutive language. In fact, they use common procedures as narration, the promise of verisimilitude, being repetitive, also, they are discourses of the "First person" speaking of experiences or of themselves. In consequence, the subject been narrated, the voice

* Professor do Programa de Filosofia da Universidade do Quindío (Colômbia). Mestre em filosofia pela Pontifícia Universidade Javeriana de Bogotá (Colômbia). Doutorando em Filosofia da Universidade de Buenos Aires (Argentina). E-mail: carlosrotten@gmail.com 
been told is an effect produced by the narration and testimony.

Keywords: Tales, Testimony, Fiction, Autobiography

\section{Resumo:}

\section{0 relato autobiográfico, entre a ficção e o testemunho}

Propomos explorar o nexo entre testemunho, autobiografia e literatura, bem como a indistinção que existe entre o relato testemunhal ou a ficção poética. Nesta linha de investigação, é útil referir-se a Demeure: Maurice Blanchot, escrito em que Jacques Derrida comenta o texto 0 instante de minha morte, para mostrar que não é possível uma distinção completa entre o registro da história, o da autobiografia e o do testemunho. Consideramos que a escrita de Blanchot mostra que a atestação tem uma relação complicada com a ficção, pois seus limites estão contaminados e que há uma indecidibilidade entre o autobiográfico e o heterotanatográfico, entre a linguagem performativa e a constativa, já que recorrem a procedimentos comuns como a narração, a promessa de credibilidade, a capacidade de repetição. São discursos em "primeira pessoa" que falam de uma experiência ou de si próprios. Consequentemente, o sujeito que é narrado, a voz que enuncia, é um efeito que é produzido pela própria narração.

Palavras-chave: História, Testemunho, Ficção, Autobiografia.

\section{Entre ficción, testimonio y autobiografía}

Algunas de las preguntas que pueden guiar este apartado son: ¿habría un sujeto de la desconstrucción? ¿Cómo relacionar a Derrida con lo autobiográfico si es un pensador que deconstruye la subjetividad? (Pelgreffi, 2013, p. 230-231). Aún más, si la escritura opera como relación con la alteridad, como huellas que no reafirman presencias, como reiteración (repetición que altera), si cuestiona la identidad del sujeto que cree dominar la escritura, el sentido, ¿cómo es posible la autobiografía? Esta son preguntas pertinentes ante la escritura derridiana en la que lo autobiográfico, lo testimonial y la confesión desbordan sus fronteras y permanecen en una doble indecidibilidad, como bien lo señala Mónica Cragnolini (2007: 32). La escritura autobiográfica tendría que ocurrir en relación con la huella y tratar con un sujeto que está marcado por la alteridad, tendría que dar cuenta de la remisión entre elementos heterogéneos, pero relacionados recíprocamente en un movimiento que conjuga lo autoremisional y la alteridad sin reunirlos en una síntesis o identidad.

Al respecto, nos resulta útil remitir a Demeure escrito en el que Derrida (1998) indaga por los límites entre el testimonio y la ficción, para mostrar que no es posible la distinción completa entre el registro del relato, de la autobiografía y el del testimonio (25). Puesto que la escritura desconstruye la figura del sujeto que se supone es objeto y "autor" de la autobiografía, así como la relación de apropiación y dominio del sujeto sobre la lengua (Derrida, 1990, p. 27). De modo que, en vez de algo propio, la lengua impone al sujeto hablante la alte- 
ridad. Estas temáticas también se abordan en Mémoires. Pour Paul de Man en relación al testimonio, la muerte, el duelo, la memoria en tanto relacionados con la indecidibilidad entre lo autobiográfico y lo heterotanatográfico, así como la oscilación indecidible entre el lenguaje performativo y el constatativo (Derrida, 1988, p. 130-131). Una consecuencia que obtenemos de esto es que el sujeto que narra, la voz que relata es un efecto producido por la narración o atestación misma.

Ahora bien, en Demeure, Maurice Blanchot Derrida remite al texto El instante de mi muerte para indagar acerca de los límites comunes entre el testimonio y la ficción. Antes de adentrarse en el texto blanchotiano, Derrida se pregunta por la herencia romana y latina de la institución literaria, por el modo en que aquello que llamamos literatura permea la cultura occidental, que es a la vez una cultura de la subjetividad que se declara, se confiesa, que sabe y que se enuncia como poseedora de un saber $\mathrm{o}$, al menos, como garante y testigo que puede dar cuenta de lo ocurrido (Derrida, 1998). El escrito de Blanchot hace ver que la atestación tiene una relación complicada con la ficción, ya que sus límites se contaminan, contradiciendo a la tradición jurídica europea para la cual el testimonio y la literatura, en tanto ficción o simulacro, deben permanecer separados (Derrida, 1998: 30).

Al igual que en "La loi du genre", en Demeure, Maurice Blanchot se plantea el carácter ficcional implícito en el testimonio, lo cual pone en contacto con la literatura, afectando su valor jurídico, pues legalmente no se aceptaría un testimonio que reconozca estar mezclado con la ficción, con el simulacro y que no se limite a describir o informar. Insistiendo sobre ese límite indecidible en el que la literatura se parásita con aquello que quiere excluir de su interior, leemos lo siguiente:

y por tanto, si lo testimonial es de derecho irreductible a lo ficcional, no hay testimonio que no implique estructuralmente en sí mismo la posibilidad de la ficción, del simulacro, de la disimulación, la mentira y el perjurio, es decir, a la literatura, a la inocente o perversa literatura que juega inocentemente a pervertir todas estas distinciones [...] Es sobre este límite indecidible que intentaremos permanecer (Derrida, 1998, p. 31).

En este contexto, surgen preguntas acerca de aquello que es el testimonio, de cuáles son sus condiciones formales. Al dar testimonio, alguien se compromete a decir la verdad, a dar cuenta de aquello excepcional que ha ocurrido y que ha presenciado. Otras condiciones son: el compromiso con lo dicho, la posibilidad de repetir lo presenciado o sabido, por ello no se limita a su parte narrativa o descriptiva, sino que "es de entrada un acto presente" (Derrida, 1998, p. 44). El testimonio es creíble no porque remite a la realidad constatable, sino a aquello que es fiable por el testimonio del otro. Por ello, es necesaria la fe o la creencia en el buen sentido e intención del narrador, así como la confianza en el movimiento progresivo del tiempo. Puesto que se pretende que el testimoniar debe ser ajeno a la mediación técnica para poder mantenerse unitario, ya que la unidad indivisible de la presencia y discurso del testigo se considera esencial; de lo contrario, si tal unidad se divide no sería confiable, pues el relato habla de lo irremplazable o no substituible, a pesar de que es necesariamente iterable.

En consecuencia, aunque se pretenda que el testimonio a viva voz trae a la presencia sin mediación alguna, la iteración es aceptada como necesaria allí donde es excluida. He aquí una gran complicación, pues 
el testimonio debe poder ser confirmado, atestiguado una y otra vez; por lo tanto, dividiéndose y multiplicándose en el tiempo; la posibilidad del testimonio es también la de su efracción y acarrea la fragmentación de lo veraz o verosímil, la virtualidad espectral del simulacro, de manera que "la posibilidad de la ficción literaria asedia como su propia posibilidad, el testimonio que se dice veraz, serio, real" (Derrida, 1998, p. 94).

Por otra parte, tenemos que el testimonio no es solo discurso biográfico sino también tanatográfico, discurso del otro y de la muerte. Lo cual nos lleva por algunos aspectos más de esta cuestión. En Le Monolinguisme de l'autre se pone en escena la alteridad que la lengua impone al sujeto hablante; a pesar de que la lengua materna u originaria se considere determinante de la identidad y de lo que le es ajeno, de lo que es para sí y lo que es externo (Derrida, 1990: 27); hablar o escribir sobre la relación con la denominada "lengua propia" es poner en cuestión la relación de apropiación y dominio del sujeto sobre la lengua. En vez de ofrecer un origen garante de la identidad, la lengua es una morada en el exilio y en la alteridad; cuestiona la autonomía y espontaneidad del sujeto que cree decir yo e identificarse a sí mismo a través de su uso de la lengua. De allí que el monolingüismo del otro sea "el hogar de esta auto-heteronomía" (Derrida, 1990 , p. 58), y que preceda incluso al sujeto del habla y de la escritura (Derrida, 1990, p. 13-14).

Estos aspectos también son prominentes en el texto "Circonfession," el cual despliega una escritura que mezcla el diario íntimo de Derrida, el duelo por la muerte de su padre, de su hermano o el duelo que se anuncia ante la enfermedad y próxima muerte de su madre. Como es habitual, se recurre al estilo del "falso diálogo" entre interlocutores indeterminados, escenificando la auto-identificación siempre diferida; se trata de una memoria de sí que tiene en la alteridad la condición antinómica de su posibilidad, que mezcla citas en latín de San Agustín con la conversación ficticia entre Derrida y su madre agonizante, con las notas del diario, las circonfesiones de un judío, árabe, magrebí, francés, que llora fácilmente (Derrida, 1991, p. 61).

Entonces, la escritura autobiográfica no se reduce al registro que hace un sujeto sobre su propia vida, pues está contaminada con la alteridad y lo mortal que la huella de escritura implica; deconstruyéndo así la figura del sujeto que se supone es objeto $\mathrm{y}$ "autor" de la autobiografía; ya que no es posible apropiar a través de la escritura ni fundar un sujeto de la pretendida apropiación; además, la vida sobre la que se intenta escribir está diferida, desplazada, enmarañada necesariamente con su mortalidad. La autobiografía y la literatura están ligadas a la confesión, sobre todo cuando sus límites no pueden ser determinados claramente, puesto que estas formas de la escritura ocurren según un imperativo del develamiento de sí, de un confesar la verdad debida sobre un sí mismo que no puede ser más que otro (Derrida, 1991, p. 72). Además, la escritura autobiográfica ocurre como duelo por un "yo" que ya está muerto, pues es la única manera de confesarlo, escribirlo, relatarlo; en el lenguaje y la escritura, duelo interminable, de una muerte siempre presente, siempre ya ocurrida y, por lo tanto, imposible a futuro.

Son estas las condiciones, para un relato que rememora sobre la relación ex-apropiante con la lengua (árabe, francés, latín) y la confusa identidad cultural y legal que hereda. En este relato Derrida intenta recordarse a "sí mismo" como un "yo" mismo, se hace evidente que la memoria es otro ele- 
mento a tener en cuenta en la ex-apropiación de la lengua, puesto que no hay testimonio, confesión ni autobiografía sin un trabajo de la memoria, sin el ejercicio que reitera y altera las huellas de lo acontecido, lo memorizado y archivado. Toda forma de memoria supone el olvido, ya que en tanto huella o marca, solo es posible porque está expuesta a ser repetida, borrada y superpuesta con otras escrituras, como ocurre con el palimpsesto, con las imágenes, con cualquier modo de la inscripción, ya que tienen en común la borradura y la repetición como rasgos que las hacen posibles. En suma, "Circonfession" es un relato de las vidas y de las muertes, de las marcas, de los cortes, de la sangre, de las oraciones y las lágrimas (Derrida, 1991, p. $42 ; 113$ ) en el que se pone en escena el carácter performativo de la escritura autobiográfica y simultáneamente hetero-tanato-gráfica.

Estas temáticas también podemos rastrearlas en Mémoires. Pour Paul de Man, pues allí se trata sobre el testimonio, la muerte, el duelo, la memoria en tanto relacionados con lo indecidible y el anacronismo en lo autobiográfico y lo heterotanatográfico. Lo que remite a una presunta oposición entre una memoria de la interioridad que idealiza y, por otra parte, una exterioridad material; se trataría entonces de dos tipos de memoria, una que interioriza e idealiza, que releva, que incluye en sí la negatividad y alteridad de lo rememorado. Y, por otra parte, una memoria que no interioriza, que no difiere al otro, que no hace el duelo pues supone la finitud de la memoria y el vestigio del otro que siempre precede, que permanece indigestible e irreductible a la síntesis totalizadora o a la narración exhaustiva. Puesto que "el otro resiste la clausura de nuestra memoria interiorizante" (Derrida, 1988, p. 44-45).
Ficción y testimonio tienen condiciones de posibilidad en común, como son la competencia y uso del lenguaje. Sus enunciados son constatativos y performativos a la vez, en tanto promesas de verdad y puesta en escena en la cual el que rinde testimonio se ofrece y expone en unas situaciones particulares para hablar en primera persona, presentándose como garante. Pero la literatura no supone el compromiso de decir la verdad ante la ley; por ello no se puede decir que alguien miente, sino que, en el testimonio, en el relato, la verdad se da u ofrece como promesa. A pesar de la aparente cercanía, el registro ficcional no puede ser aceptado como una prueba legal. Blanchot y Derrida nos llevan a problematizar las categorías en las que nos confiamos cuando se intenta excluir la ficción y el arte de lo testimonial, ya que el testimonio no es solo un ejercicio para constatar hechos, sino que es un acto performativo, de creación poética. Puesto que estos límites no son tan claros; son, de algún modo, reversibles entre sí, indecidibles, como se indica a continuación,

alusión entonces evidente a una distinción entre ficción y autobiografía que no solo permanece indecidible, sino que, lo que es más grave, en la indecidibilidad de la cual, precisa de Man, es imposible mantenerse de modo estable o permanente. Nos encontramos entonces en una imposibilidad doble y fatal: imposibilidad de decidir así como imposibilidad de permanecer en la indecidibilidad (Derrida, 1998, p. 10-11).

Según lo recientemente planteado acerca de la indecidibilidad entre el relato y lo autobiográfico, lo constatativo y lo performativo, llas divisiones tiemblan, el testimonio no es solo constatativo, tiene también una fuerza performativa que no se puede ignorar, dado que su condición de posibilidad es poética. Pues, como sostiene Derrida, "hay un genio 
que retorna y que nos recuerda que el acto testimonial es poético o no lo es, dado que debe inventar su lenguaje y sus formas en un performativo inconmesurable" (Derrida, 1998, p. 109), por ello el testigo debe ajustarse a los criterios de lo testimonial pero simultáneamente "inventar, de modo cuasi-poético, las normas de su declaración" (Derrida, 1998, p. 46).

\section{Relatos del otro y la muerte}

La alteridad y la muerte ponen en entredicho la pretensión de establecer los límites del género autobiográfico, es decir, de los relatos acerca de un sí mismo y su vida, puesto que lo indecidible está en juego en el entre del sí mismo y lo otro, así como entre la vida y la muerte. Es en este escenario problemático que se comenta L'instant de ma mort de Maurice Blanchot, escrito que según el tiempo dramático del relato está fechado en 1944 , a finales de la segunda guerra mundial, y que trata acerca de un joven que estuvo a punto de ser fusilado. Derrida duda de que se trate simplemente de un relato ficticio y propone seguir las huellas testamentarias, jugando con los indicios que van desde lo ficcional hacia lo testimonial y lo biográfico, gracias a algunas menciones de una carta de 1994 en la que Blanchot dice que 50 años atrás, un 20 de julio, estuvo a punto de morir; lo que desplaza la narración hacia la atestación de algo ocurrido y conocido, la ocupación nazi, los movimientos de resistencia. Entonces, se trata de otro registro de escritura que lleva a lo indecidible los límites que quieren trazarse. De allí que Derrida señale respecto a L'Instant de ma mort, que no sabe "si pertenece o no, de manera pura y propia, estricta y rigurosa, al espacio de la literatura, si es una ficción o un testimonio, y sobretodo, hasta qué punto cues- tiona o hace temblar todas estas divisiones" (Derrida, 1998, p. 25).

En L'Instant de ma mort se cuenta que una tarde de verano europeo, todos los moradores de una vivienda denominada el "castillo" fueron llevados fuera por un grupo de soldados aparentemente nazis; luego de permitir que las mujeres y los niños regresaran al interior del lugar, algunos jóvenes fueron dispuestos para el fusilamiento, pero el ruido de las balaceras y bombas en el entorno distrajeron al teniente en el momento en que ya los fusiles apuntaban listos para disparar. En medio de la confusión y el descuido, un soldado da al joven la oportunidad de irse, después de decir que no son alemanes y revelar su procedencia: eran mercenarios rusos de la Armada Vlassov (Blanchot1999, p. 19-20). Las tropas se retiran sin incendiar el castillo, como había ocurrido con otras de las viviendas al rededor, mientras que el joven se reguarda en el bosque, donde permanece hasta recuperar el sentido de lo real (Blanchot,1999,p. 21).

Según comenta Derrida, fue esta una experiencia o un instante de ligereza ante una muerte imposible, imposibilitada, siempre venidera; muerte anterior e incierta, que remite a un pasado sin presente y no individual, a un instante no idealizado, sino puesto en demora; desde siempre diferida, tanto a futuro como en el pasado. Efectivamente, "es de este extraño acontecimiento que un texto como este da testimonio, de un modo, vamos a verlo, abisal, elíptico, paradójico y, además, indecidible" (Derrida, 1998, p. 65). Esto supone la anacronía de un tiempo fuera de goznes y se marca en esta frase que remite a La escritura del desastre: "yo muero antes de haber nacido", con la que se cuestiona la inminencia de lo que ya ha tenido lugar. 0 como lo formula Blanchot en estas líneas: "qué importa. Tan sólo permanece 
el sentimiento de ligereza que es la muerte misma o, para decirlo con más precisión, el instante de mi muerte desde entonces siempre pendiente" (Blanchot 2004, p. 26).

Se marca de este modo el anacronismo intrínseco el testimonio, pues son diferentes temporalidades las que se encuentran imbricadas, dividiendo el instante y poniendo al tiempo fuera de goznes, a causa de la simultaneidad de la multiplicación y la suspensión. Además de la cuestión temporal, Derrida hace algunas observaciones respecto a la voz que narra y al presunto "sujeto" del relato. Aunque el narrador presenta al joven como una tercera persona, su acto de memoria está escrito inicialmente en primera persona, por ello podemos leer al inicio de dicho texto: "me acuerdo de un joven - un hombre todavía joven - privado de morir por la muerte misma -y quizás el error de la injusticia-" (Blanchot, 2004, p. 17). Aquel hombre joven pudo ser el mismo Blanchot, quien ahora no podía reconocerse como el sujeto-autor del relato y de tal experiencia, pues la escritura supone la división del tiempo y del sujeto, su estar out of joint. A lo cual tenemos que agregar que, según Derrida, Blanchot plantea una imposibilidad del presente que trastoca el tiempo, lo anacroniza haciendo que el pasado se enmarañe con las huellas del futuro o venidas del porvenir (Derrida, 1998, p. 107); de modo el testimonio como memoria es una promesa de futuro, algo que no existe ni responde al presente (Derrida, 1988, p. 68). Esto supone la división del instante según ritmos discontinuos, según la retórica del tiempo y del espacio, irreductibles a algún modo de la presencia.

¿Pero cómo dar, entonces, testimonio de la propia muerte si remite a un pasado que nunca ha ocurrido? En esta cultura de la "confesión de sí”, de la subjetividad que se enuncia al atestiguar, que promete decir la verdad e inventa a la vez un relato, solo se puede testimoniar en primera persona, pero para ello se debe sobrevivir a lo acontecido y relatado, de modo que, incluso las huellas testamentarias sobreviven a la muerte del firmante y son siempre "memorias de ultratumba" (Derrida, 1988, p. 111).

Esto también es planteado en relación con Paul De Man y la indagación por la autobiografía, ya que las memorias de sí no son necesaria y exclusivamente confesionales, sino también performativas; ya que "lejos de garantizar ninguna identificación con el self o de congregarse alrededor del self, esta estructura especular implica una dislocación tropológica que impide toda totalización anamnésica del self' (Derrida, 1988, p. 35), imposibilidad de producir la promesa y el sí mismo. En esto consiste la perversa ambigüedad e impureza del performativo, en las que se ponen en suspenso las fronteras entre la literatura y sus otros; precisamente,

es ahí que el falso testimonio y la ficción literaria pueden incluso testimoniar verdaderamente, al menos a título de síntoma, por lo tanto, la posibilidad de la ficción habrá estructurado, a modo de fractura, aquellos que llamamos la experiencia real [...] Pero queda que, debemos decirlo tan firmemente, esta indecidibilidad, como las co-implicaciones abisales que ella genera, no invalida en nada la exigencia de veracidad, de sinceridad o de objetividad, tampoco autoriza la confusión entre la buena fe y el falso testimonio (Derrida, 1998, p. 123-124).

Por otra parte, tenemos que toda escritura, es de algún modo un epitafio, al igual que toda inscripción idealizante o autobiográfica es olvido de sí y memoria del otro, debido a que "el discurso y la escritura funeraria no siguen a la muerte; trabajan sobre la vida en lo que llamamos autobiografía. Y tienen lugar entre la ficción y la verdad, Dichtung 
und Warheit" (Derrida, 1988, p. 34). Por consiguiente, desde la lectura derridiana, todo relato es necesariamente hetero-tanato-gráfico o como dice en cierto momento, hosto-tanato-gráfico: el relato del otro, de un huésped o rehén, del estar cautivo, de la muerte (Derrida, 1998, p. 52).

Por último, señalamos que lo indecidible y lo neutro tienen en común poner en suspenso las dualidades jerárquicas, lo que impide elegir sin implicar o excluir simultáneamente las alternativas que se contaminan (doble negación y doble afirmación); es entonces cuestión del tercero no excluso, un pensamiento no regido por el principio de no contradicción, que no es asunto del cálculo del sujeto sino de lo incalculable y del otro. Por lo cual,

no hay más allá de lo indecidible, pero este más allá permanece no obstante para ser pensado desde "este punto de 'referencia' un poco más confiable"; y uno sólo puede involucrarse así en una promesa, dando la propia palabra sobre este tema, aun si uno la niega al afirmarla irónicamente. Queda por pensar la indecidibilidad, una que ya no está vinculada al orden del cálculo entre dos polos de oposición; sino al orden incalculable de un totalmente otro: el advenimiento o la convocación de lo otro. Tiene que ser imprevisible, aleatorio más allá de todo calculo. No hay dentro -de-lo-indecidible, pero una memoria otra nos convoca, nos remite a pensar un "acto" o "parole", o un "acto de habla" que resiste la oposición performativo/constatativo, provocando al mismo tiempo la aporía y movimiento hacia adelante, la marcha, la relación de uno con el otro, es decir, la historia del texto (Derrida, 1988, p. 139-140).

La indecidibilidad remite al componente negativo con el que se asocia regularmente lo neutro, en tanto doble negación, movimiento del ni/ni, pero también, busca allí no solo la doble muerte, la negación como muerte, sino también una afirmación gozo- sa y excesiva de la vida, de otra vida, pues no solo se ha liberado de la vida sino de la muerte misma. Entonces, la indecidibilidad, que "es la condición de la deconstrucción" (Derrida, 1988, p. 137-138), es entendida como una oscilación que avanza y que problematiza la diferenciación entre el lenguaje performativo y constatativo, entre los géneros, entre la literatura y filosofía, entre el yo y la ficción, como ya había sido anticipado por Nietzsche (Cragnolini, 2007: 32). Se trata de la fractura desestructurante y el principio de contaminación que está implicado en la ley de los géneros; asimismo, de la ley espectral que desborda la oposición y la negatividad, el pensamiento del $X \sin X$, de la muerte sin muerte, del testimonio sin testimonio o el relato sin relato, de la no relación, que atendiendo a los conceptos de Blanchot podemos denominar lo neutro, puesto que "esta liviandad del "sin", el pensamiento de la ' $\mathrm{X}$ ' $\sin$ ' $\mathrm{X}$ ' viene a firmar, consignar y contrafirmar, al asemejársele, la experiencia de lo neutro como neuter, ni-ni (Derrida, 1998, p. 120).

Al iniciar este artículo, interrogamos acerca de la relación entre deconstrucción de la subjetividad y el relato autobiográfico, resaltando que pueden parecer asuntos incompatibles. Sin embargo, hemos mostrado que la escritura derridiana y blanchotiana no se limitan a una crítica del sujeto fundacional con la pretensión de prescindir o eliminar cualquier figura de la subjetividad; por el contrario, encontramos que en la escritura del relato y en las narraciones autobiográficas, tanatográficas y heterobiográficas se producen performativamente versiones no sustanciales de la subjetividad, en tanto que no son el polo fundador de la narración misma, sino que son efectos de la escritura y del relato. Efectivamente, los escritos derridianos y blanchotianos men- 
cionados ponen en juego la exigencia testamentaria de la escritura y la imposibilidad de la veracidad autobiográfica, pues la escritura sería más bien la auto y hetero-tanato-grafía. Asimismo, trastocan la temporalidad de la narración, ponen el tiempo fuera de goznes ya que el performativo inconmensurable del testimonio se dé también como acto poético. Es en estas tensiones y en el suspenso errante de un pensamiento de lo neutro y lo indecidible que la escritura de Derrida y de Blanchot intentan demorarse.

\section{Bibliografía}

BLANCHOT, Maurice. El instante de mi muerte, La locura de la luz. trad. A. L de Samaniego. Madrid: Técnos, 1999

BLANCHOT, Maurice. El paso (no) más allá, trad. C. de Peretti. Barcelona: Paidós, 1994.

BLANCHOT, Maurice. La parte del fuego. Trad. I. Herrera. Arena Libros: Madrid. 2007

BLANCHOT, Maurice. "Nietzsche y la escritura fragmentaria". Revista Instantes y azares. Escrituras Nietzscheanas, Buenos Aires, v. 12, n.11, p. 27-51.

BLANCHOT, Maurice. Tiempo después. Precedido por La eterna reiteración. Madrid: Arena Libros, 2003.

DERRIDA, Jacques. “Circonfesión”. En: Bennington, Geoffrey; Derrida, Jacques Jacques Derrida. Paris: Seuil, 1991.

DERRIDA, Jacques. De la grammatologie. Paris: Minuit. 1967

DERRIDA, Jacques. Demeure. Maurice Blanchot. Paris: Galilée, 1998
DERRIDA, Jacques. Demeure. Athènes. Paris: Galilée, 2009

DERRIDA, Jacques. La dissémination. Paris: Seuil, 1972

DERRIDA, Jacques. Le Monolinguisme de l'autre, Paris: Galilée, 1996

DERRIDA, Jacques. Limited inc. Illinois: Northwestern University Press, 1987

DERRIDA, Jacques. Marges - De la philosophie. France: Minuit, 1972

DERRIDA, Jacques. Mémoires d'aveugle. L'autoportrait et autres ruines. Paris: Éditions de la Réunion des Musées Nationaux, 1990.

DERRIDA, Jacques. Mémoires. Pour Paul de Man. Paris: Galilée, 1988

DERRIDA, Jacques. Parages. Paris: Galilée,1986

DERRIDA, Jacques. This strange institution called literature. En: Attridge, Derek (Ed.), Acts of literature. New York, Routledge. pp. 3375, 2002.

FISGATIVA, Carlos. "La escritura como diseminación y composición a partir de Derrida y Mallarmé". Cadernos Literários. v. 25, n 1. P. 13-18, 2017.

PELGREFFI, Igor. "Animale autobiografico. Derrida e la scrittura dell'autos". Lo Sguardo. N. 11.v. 1. p. 228-298, 2013.

SHUN-LIANG, Chao. "Derrida's Deconstruction and the Rhetoric of Proper Genres in Leonardo and Lessing". Comparative Literature and Culture, v. 8, n 3, p. 1-8, 2006. Disponible en http://dx.doi.org/10.7771/1481-4374.1313

Recebido em: 16/10/2020

Aprovado em: 30/11/2020 